\title{
IMPLEMENTASI TRAUMA HEALING DALAM PENANGANAN ANAK KORBAN TINDAK PIDANA KEKERASAN SEKSUAL
}

\section{IMPLEMENTATION OF TRAUMA HEALING IN HANDLING OF CHILDREN VICTIMS IN CRIMINAL ACTIONS OF SEXUAL VIOLENCE}

\author{
Imam Maulana Yusuf ${ }^{1 *}$, Siti Fatimah ${ }^{2}$, Evi Noviawati ${ }^{3}$ \\ ${ }^{1}$ FISIP Universitas Galuh \\ ${ }^{2}$ Fakuktas Ilmu Kesehatan Universitas Galuh \\ ${ }^{3}$ Fakultas Hukum Universitas Galuh \\ *Email: tifisipunigal@gmail.com \\ (Diterima 22-01-2021; Disetujui 22-02-2021)
}

\begin{abstract}
ABSTRAK
Mitra dalam kegiatan PKMS ini adalah PKK Desa Pajaten Kecamatan Sidamulih Kabupaten Pangandaran. Pemasalahan mitra adalah sebagai berikut: 1) Kader PKK Desa Pajaten Kecamatan Sidamulih Kabupaten Pangandaran belum memahami pengetahuan mengenai kekerasan seksual pada anak; 2) Belum optimalnya Keterlibatan Kader PKK Desa Pajaten Kecamatan Sidamulih Kabupaten Pangandaran dalam implementasi Trauma Healling dikarenakan sehingga tidak dapat membantu dalam penanganan terhadap anak korban kekerasan seksual; 3) Semakin banyaknya anak korban kekerasan seksual dalam kurun waktu 2017-2019 sehingga berpengaruh terhadap kekhawatiran lingkungan Desa Pajaten Kecamatan Sidamulih Kabupaten Pangandaran; 4) Kurangnya sikap aktif dan peduli terhadap sebuah kejadian yang tidak sesuai dengan aturan dan harus diselesaikan secara cepat dan tepat. Solusi yang ditawarkan untuk mengatasi permasalahan mitra yakni memberikan Pemahaman dan pelatihan penerapan metode Trauma Healing untuk anak korban tindak pidana kekerasaan seksual bagi Kader PKK Desa Pajaten Kecamatan Sidamulih Kabupaten Pangandaran. Penerapan metode Trauma Healing merupakan bentuk penanganan awal berupa bantuan psikologis bagi anak yang mengalami gejala Post Traumatic Stress Disorders (PTSD) akibat dari adanya tekanan atau goncangan mental yang disebabkan tindakan kekerasaan. Penerapan metode Trauma Healing yang praktis dapat dilakukan oleh keluarga, yaitu melalui terapi permainan (play therapy) dan motivasi diri (self motivation). Penggunaan metode Trauma Healing berupa terapi bermain (play therapy) lebih menekankan pada permainan yang syarat akan muatan edukasi dan dirancang agar dapat menuangkan simbolisasi tekanan atau kondisi traumatis bagi anak dan sekaligus sebagai adaftasi stres. Sedangkan metode motivasi diri (self motivation) yang bertujuan untuk meningkatkan motivasi diri bagi anak korban kekerasan seksual agar tidak mengalami ganguan hilang kepercayaan diri sehingga dapat bangkit dan semangat berkarya dalam rangka membangun masa depan yang lebih baik.
\end{abstract}

Kata Kunci : Kekerasan Seksual, Trauma Healing

\section{ABSTRACT}

Partner in the activities of People with Social Welfare Problems is Empowering Family Welfare in Pajaten Village, Sidamulih District, Pangandaran Regency. The problems of partner are as follows: 1) Cadre of Family Welfare Empowerment in Pajaten Village, Sidamulih District, Pangandaran Regency does not yet understand the knowledge about sexual violence against children; 2) The involvement of the Cadre of Family Welfare Empowerment in Pajaten Village, Sidamulih District, Pangandaran Regency in the implementation of Trauma Healing is not optimal because it is unable to assist in handling child victims of sexual violence; 3) The increasing number of child victims of sexual violence in the 2017-2019 period so that it affects environmental concerns in Pajaten Village, Sidamulih District, Pangandaran Regency; 4) Lack of active and caring attitude towards an incident that is not in accordance with the rules and must be resolved quickly and precisely. The solution offered to solve partner problems is to provide understanding and training on the application of the Trauma Healing method for child victims of sexual violence for the Family Welfare Empowerment Cadre of Pajaten Village, Sidamulih District, Pangandaran Regency. The application of the Trauma Healing method is a form of early treatment in the form of psychological assistance for children who experience symptoms of Post Traumatic Stress Disorders (PTSD) due to pressure or mental shocks caused by violent acts. The practical application of the Trauma Healing method can be done by families, namely through play therapy and self-motivation. The use of the Trauma Healing method in the form of play therapy emphasizes more on games that require educational content and are designed to symbolize stress or 
traumatic conditions for children and at the same time as an adaptation of stress. Meanwhile, the method of self-motivation which aims to increase self-motivation for child victims of sexual violence so as not to experience disruption of loss of self-confidence so that they can rise and the spirit of work in order to build a better future.

Keywords : Sexual Violence and Trauma Healing

\section{PENDAHULUAN}

Perlindungan hukum terhadap anak dapat diartikan sebagai upaya perlindungan hukum terhadap berbagai kebebasan dan hak asasi anak (fundamental rights and freedoms of children) serta berbagai kepentingan yang berhubungan dengan kesejahteraan anak. Kekerasan seksual terhadap anak dikenal dengan istilah child sexual abuse. Dalam banyak kejadian, kasus kekerasan seksual terhadap anak sering tidak dilaporkan kepada kepolisian. Kasus tersebut cenderung dirahasiakan, bahkan jarang dibicarakan baik oleh pelaku maupun korban. Para korban merasa malu karena menganggap hal itu sebagai sebuah aib yang harus disembunyikan rapat-rapat atau korban merasa takut akan ancaman pelaku. Sedangkan si pelaku merasa malu dan takut akan dihukum apabila perbuatannya diketahui. Eksistensi dan posisi korban tindak pidana dalam sistem peradilan pidana tidak menguntungkan bagi korban tindak pidana, karena terbentur dalam problem yang mendasar yakni korban hanya sebagai saksi dan pelapor (Gorda, 2017). Keengganan pihak keluarga melaporkan kasus kekerasan seksual pada anak yang dialami, bisa jadi merupakan salah satu sebab kasus tersebut terjadi seperti fenomena gunung es, karena yang tampak hanya sebagian kecil saja, sedangkan sebagian besar tidak tampak (Majalah Prospek, 2010).

Kekerasan fisik maupun kekerasan psikis bisa menimbulkan trauma pada perasaan seseorang. Seseorang yang pernah merasakan penganiayaan pada masa kecil akan menunjukan sifat pendiam, curiga, takut, menjadi keras, dan sebagainya. Bentuk dari kekerasan fisik bisa memukul, menampar, mencekik, dan sebagainya. Sedangkan kekerasan psikis bisa berupa ungkapan kasar seperti, mengejek, cemoohan, dan sebagainya. Kekerasan seksual termasuk di dalam kategori ini. Tidak hanya mengakibatkan kerusakan fisik, tetapi juga mengakibatkan kerusakan psikis. Kerusakan fisik bisa dengan mudah diketahui ataupun diidentifikasi, namun kerusakan psikis sulit sekali untuk diidentifikasi dan memperlukan ketelitian yang mendalam. Apabila kerusakan ini tidak segera ditangani dengan benar, maka kemungkinan besar akan mengarah pada gejala Post Traumatic Stress Disorders (PTSD). 
The parties involved in child protection are the government, schools, communities, the children themselves and non-governmental organizations (Banks, et al, 2017). Dampak yang muncul dari kekerasan seksual kemungkinan adalah depresi, fobia, mimpi buruk, curiga terhadap orang lain dalam waktu yang cukup lama, membatasi diri dengan lingkungan. Bagi korban perkosaan yang mengalami trauma psikologis yang sangat hebat, ada kemungkinan akan merasakan dorongan yang kuat untuk bunuh diri. Dampak bagi korban kekerasan seksual tidak hanya dampak fisik, akan tetapi dampak psikologis. Secara fisik memang mungkin tidak ada hal yang harus dipermasalahkan pada anak yang menjadi korban kekerasan seksual, tapi secara psikis bisa menimbulkan ketagihan, trauma, pelampiasan dendam, dan lain-lain. Apa yang menimpa mereka akan mempengaruhi kematangan dan kemandirian hidup anak di masa depan, caranya melihat dunia serta masa depannya secara umum. Terdapat keterkaitan antar aspek kognitif, sosial, dan afeksi yang bereaksi dan berproses terhadap stimulus yang ada dan memunculkan perasaan negatif, serta adanya peran proses kognitif dalam menentukan perilaku yang dimunculkan. Pengaktifan salah satu komponen akan mengaktifkan komponen lainnya yang kemudian menentukan respon seseorang terhadap stimulus yang dihadapi (Utami, 2018).

Selanjutnya, dari hasil pengamatan awal terkait dengan kasus kekerasaan seksual yang terjadi di wilayah hukum Kabupaten Ciamis. Salah satunya terjadi di Kabupaten Pangandaran dimana dalam kurun waktu dari tahun 2017-2019 khususnya mengenai kekerasan seksual terhadap anak terjadi peningkatan. Namun, dari beberapa kasus tentang kekerasaan seksual pada anak yang terjadi di Kabupaten Pangandaran, yang menarik perhatian karena kondisi real menunjukan kekerasan seksual yang terjadi di Desa Pajaten Kecamatan Sidamulih Kabupaten Pangandaran dilakukan oleh seorang (oknum) guru ngaji dimana seharusnya membimbing dan mendidik anak-anak dengan perilaku yang baik dan mengajarkan norma agama dalam kehidupan serta merupakan contoh bagi muridmuridnya. Tentunya dengan adanya kejadian tersebut menimbulkan kecemasan dan keresahan bagi lingkungan sekitar yang dikhawatirkan akan berdampak baik dalam hal pisik ataupun psikis.

Menurut beberapa penelitian bahwa dengan adanya anak-anak sebagai korban kekerasan seksual akan berdampak pada psikologis yang dibagi menjadi dua kategori, yang pertama adalah ketagihan untuk melakukan hal tersebut, dan yang kedua adalah akan berpotensi sebagai pelaku di masa yang akan datang. Sehingga tentunya diperlukan upaya 
untuk mengatasi dan mencegah terjadinya hal serupa waktu yang akan datang, maka dapat dilakukan melalui kegiatan Trauma Healing terhadap anak korban kekerasan seksual.

Trauma Healing merupakan salah satu metode penanganan anak korban kekerasan seksual yakni fase yang diterapkan pada proses pemulihan diri (umumnya dari gangguan psikologis, trauma, dll), didorong oleh dan diarahkan oleh diri sendiri, namun sering kali hanya dipandu oleh insting. Proses tersebut menghadapi nasib campuran karena sifat amatir, meskipun motivasi diri merupakan aset utama. Nilai penyembuhan diri terletak pada kemampuannya untuk disesuaikan dengan pengalaman unik dan persyaratan individu. Proses ini dapat membantu dan dipercepat dengan teknik introspeksi. Trauma Healling suatu metode penyembuhan pada gangguan psikologis yang dialami oleh seseorang karena lemahnya ketahanan fungsi-fungsi mental (Andreas, dkk., 2017).

Atas dasar hal itu, mendorong tim pengabdian kepada masyarakat dari Universitas Galuh untuk melakukan kegiatan pengabdian yang dikemas dalam bentuk Program Kemitraan Masyarakat Stimulus (PKMS) dari DRPM Kemenristek-Brin yang berkerjasama dengan mitra kelompok PKK di Desa Pajaten Kecamatan Sidamulih Kabupaten Pangandaran. Selama ini, kelompok PKK Desa Pajaten Kecamatan Sidamulih Kabupaten Pangandaran, dipandang dapat berperan aktif dalam upaya mengatasi dan mencegah terjadinya tindak kekerasaan seksual pada anak, karena satu satunya organisasi masyarakat yang dapat bersentuhan dan berhubungan secara langsung dengan masyarakat. Namun kendati demikian, kelompok PKK Desa Pajaten Kecamatan Sidamulih Kabupaten Pangandaran masih dihadapkan dengan beberapa permasalahan dalam hal penanganan dan pencegahan tindak pidana kekerasan seksual pada anak, diantaranya:

1. Kader PKK Desa Pajaten Kecamatan Sidamulih Kabupaten Pangandaran belum memiliki pengetahuan terkait dengan tindakan pindana yang termasuk ke dalam kekerasan seksual pada anak;

2. Pemahaman mengenai metode Trauma Healing terhadap anak korban kekerasan seksual masih rendah

3. Kurangnya sikap aktif dan peduli terhadap sebuah kejadian yang tidak sesuai dengan aturan dan harus diselesaikan secara cepat dan tepat.

Atas dasar permasalahan tersebut sekiranya perlu dilakukan sebuah pemahaman berupa implementasi Trauma Healing terhadap anak korban kekerasan seksual yang sasaran utamanya adalah kader PKK Desa Pajaten Kecamatan Sidamulih Kabupaten Pangandaran. Dengan dilakukannya kegiatan Implementasi Trauma Healling pada Anak Korban 
kekerasan seksual akan bisa meminimalisir berdampak pada anak seperti akan terbunuh karakternya, akan melahirkan trauma berkepanjangan yang kemudian dapat melahirkan sikap tidak sehat, seperti minder, takut yang berlebihan, perkembangan jiwa terganggu, dan akhirnya berakibat pada keterbelakangan mental. Selain itu dengan adanya kegiatan ini dapat membantu pemerintah dalam memberikan informasi dan pengetahuan kepada masyarakat khususnya Kader PKK Desa Pajaten Kecamatan Sidamulih Kabupaten

\section{BAHAN DAN METODE}

Pelaksanaan kegiatan pengabdian kepada masyarakat yang dikemas dalam bentuk Program Kemitraan Masyarakat Stimulus (PKMS) menggunakan metode pendampingan dalam meningkatkan pengetahuan dan pengembangan pola pikir mitra sehingga dapat lebih meningkatkan kapasitas dan kemampuan diri atau life skill. Adapun tahapan dari pelaksanaan kegiatan tersebut meliputi: 1) Sosialisasi, 2) Penjelasan dan Implementasi Trauma Healing pada penanganan Anak Korban Kekerasan Seksual, dan 3) Evalusi dan Tidak Lanjut.

\section{HASIL DAN PEMBAHASAN}

Pada pelaksanaan metode pertama, berupa sosialisasi mengenai pemberian informasi atas kegiatan Program Kemitraan Masyarakat Stimulus (PKMS) kepada pihak pemerintah Desa Pajaten Kecamatan Sidamulih Kabupaten Pangandaran dan mitra yaitu, kader penggerak kelompok organisasi kemasyarakat PKK. Pada tahapan kegiatan awal ini tim pelaksana PKMS melakukan strategi pendekatan kepada Pemerintah Desa Pajaten Kecamatan Sidamulih Kabupaten Pangandaran, dengan menjelaskan alur pelaksanaan serta meminta dukungan selama kegiatan dilaksanakan.

Adapun dari hasil pelaksanaan kegiatan pada tahap satu ini, diperoleh beberapa gambaran mengenai respon dari mitra atas pelaksanan kegiatan PKMS yang dapat diuraikan sebagai berikut:

1. Mitra sangat menerima dengan menujukan sikap kekeluargaan terhadap tim PKMS;

2. Mitra sangat terbuka dengan adanya kegiatan PKMS dan siap untuk membantu terselenggarakannya kegiatan sampai dengan selesai;

3. Mitra bersedia memberikan dukungan dalam hal penyediaan tempat dan fasilitas untuk pelaksanaan kegiatan PKMS. 

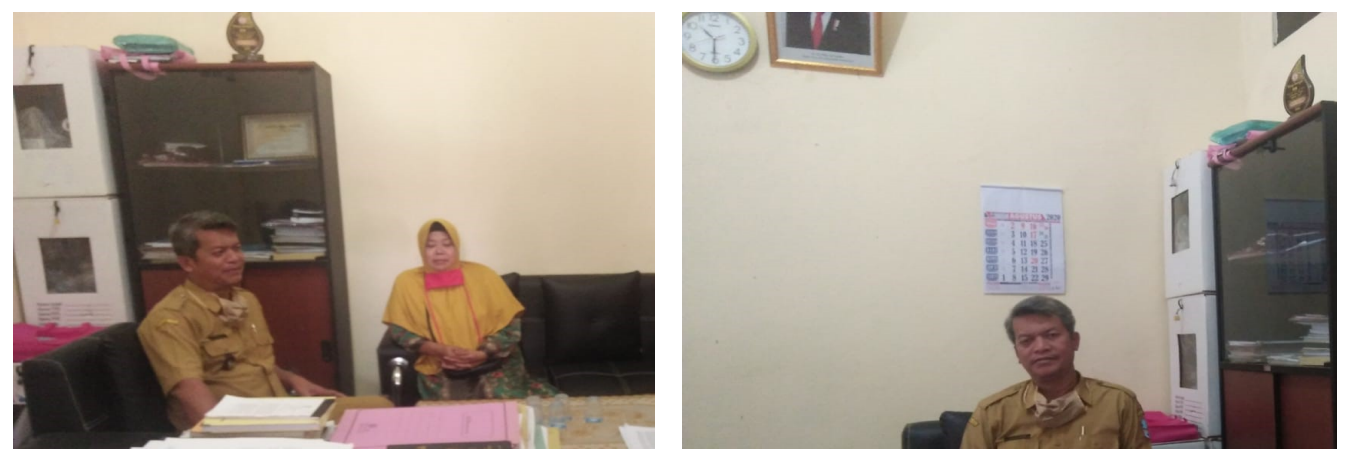

Gambar 1. Sosialisasi Pelaksanaan Kegiatan Dengan Mitra dan Pemerintah Desa Pajaten Kecamatan Sidamulih Kabupaten Pangandaran

Selanjutnya setelah dilaksanakan tahapan pertama, maka tim pelaksana melakukan kegiatan penyuluhan dan pemberian contoh dalam penerapan metode penanganan untuk anak korban tindak kekerasaan seksual melalui metode Play Therapy dan Pembentukan Self Motivation dalam mengurangi dampak psikologis dengan mitra sasaran kelompok PKK Desa Pajaten Kecamatan Sidamulih Kabupaten Pangandaran.

Pada tahapan ini dilaksanakan di Aula Desa Pajaten Kecamatan Sidamulih Kabupaten Pangandaran dan dihadiri sebanyak 20 orang peserta. Pada kesempatan ini dilakukan pula pengukuran mengenai tingkat keberhasilan dari pelaksanaan kegiatan, dengan terlebih dahulu menyebarkan lembar soal sebagai bentuk pre-test yang terdiri atas 10 pertanyaan dengan tipe pilihan jawaban ya dan tidak yang tujuannya untuk mengukur pemahaman awal mitra. Selanjutnya setelah itu, dilakukan penyuluhan berupa pemberian materi dan dialanjutkan dengan pemberian contoh penanganan Trauma Healing bagi anak korban tindak kekerasaan seksual melalui Play Therapy dan Pembentukan Self Motivation.
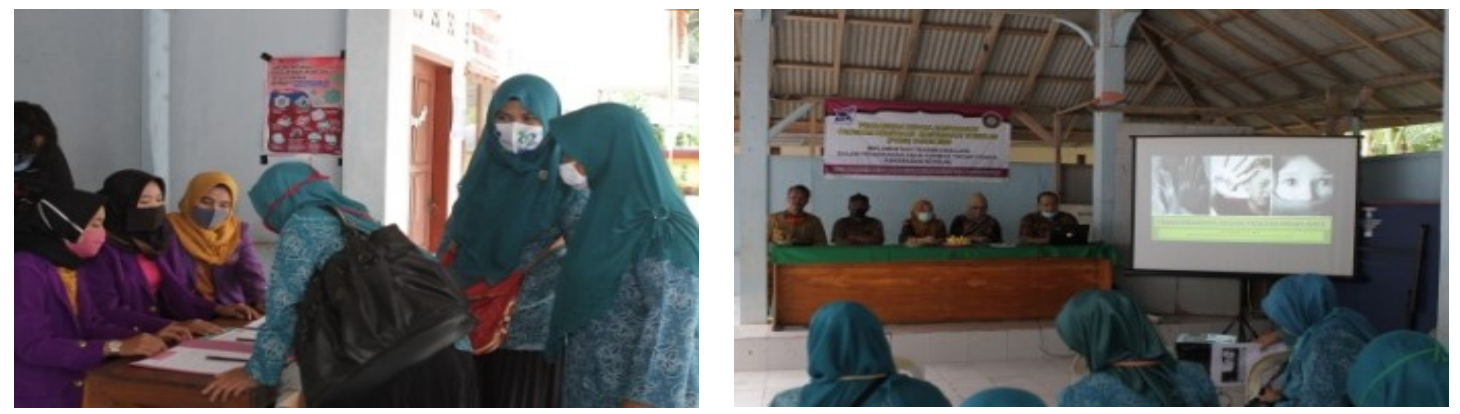

Gambar 2. Kegiatan Penyuluhan Kepada Mitra Mengenai Trauma Healing Bagi Anak Korban Tindak Kekerasan Seksual

Setelah dilakukan penyuluhan, selanjutnya peserta diberikan beberapa contoh metode penanganan untuk anak korban tindak kekerasaan seksual melalui metode Play Therapy dan Pembentukan Self Motivation dalam mengurangi dampak psikologis sebagai bentuk 
peningkatan kapasitas dan kemampuan mitra dalam mencegah dan mengatasi terjadinya depresi serta Post Traumatic Stress Disorder (PTSD) pada anak yang diakibatkan oleh adanya tindakan kekerasaan.
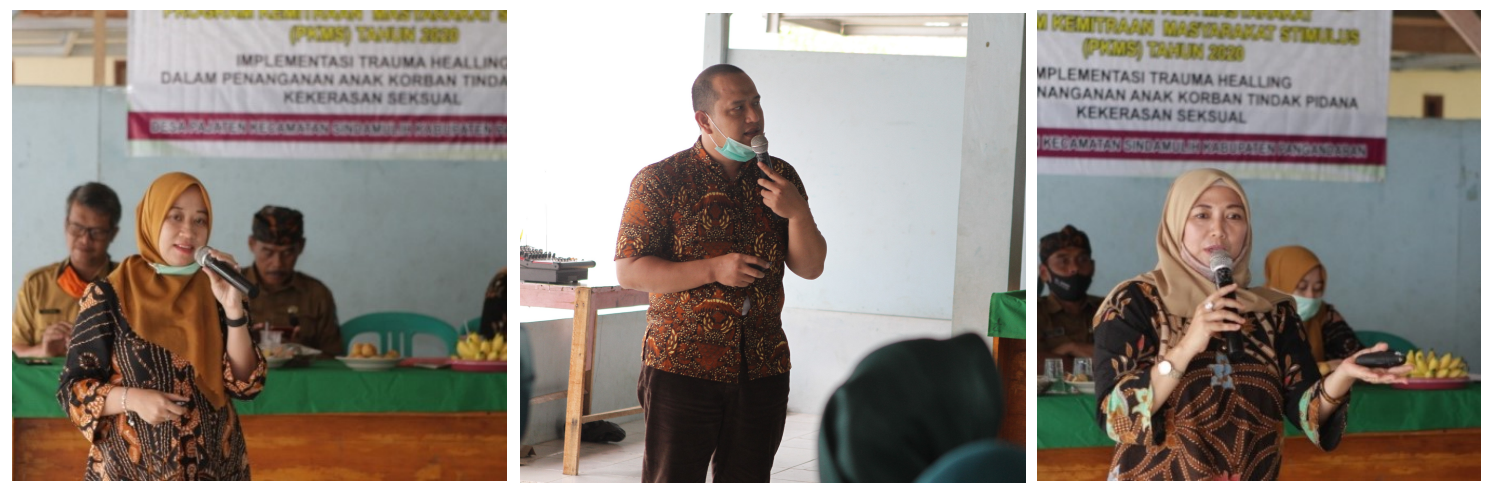

Gambar 3. Penjelasan dan Pemberian Contoh Penanganan Anak Korban Tindak Kekerasaaan Seksual Melalui Play Therapy dan Pembentukan Self Motivation

Pada kegiatan penyuluhan dan pemberian contoh penanganan anak korban tindak kekerasaan seksual melalui Play Thrapy dan Pembentukan Self Motivation, untuk mempermudah penyampaian materi diberikan pula modul agar dapat dipelajari secara mandiri. Disamping itu, pada kesempatan ini dilakukan pula diskusi dan tanya jawab untuk lebih memperdalam pemahaman. Setelah itu, peserta diberikan lembar soal yang sama untuk diisi kembali sebagai bentuk post-test guna mengetahui tingkat keberhasilan peningkatan kemampuan mitra.

Dari hasil uji beda atau (t-test) atas hasil jawaban pre-test dan post-test dalam mengukur kemampuan dan keberhasilan penerapan IPTEK terhadap mitra sasaran kegiatan, diperoleh hasil sebagaimana terlihat pada Tabel 1.

Tabel 1. Hasil uji beda (t-test) tingkat pemahaman mitra atas penerapan metode Trauma Healing pada anak korban tindak kekerasan seksual

\begin{tabular}{|c|c|c|c|c|c|c|c|}
\hline Pemahaman Mitra & Kondisi & $N$ & Mean & Std. Deviation & Min & $\operatorname{Max}$ & Sig \\
\hline \multirow{2}{*}{$\begin{array}{l}\text { Mengenali Bentuk } \\
\text { dan Jenis } \\
\text { Kekerasaaan Pada } \\
\text { Anak }\end{array}$} & Sebelum & \multirow{2}{*}{20} & 22.6500 & 8.26709 & 14.00 & 41.00 & 000 \\
\hline & Sesudah & & 41.2500 & 6.87386 & 27.00 & 48.00 & 000 \\
\hline \multirow{2}{*}{$\begin{array}{l}\text { Penanggulangan } \\
\text { Dampak Trauma } \\
\text { Bagi Anak Korban } \\
\text { Tindak Kekerasaan } \\
\text { Seksual }\end{array}$} & Sebelum & \multirow[b]{2}{*}{20} & 30.6500 & 8.17103 & 18.00 & 45.00 & 000 \\
\hline & Sesudah & & 40.3500 & 6.88457 & 25.00 & 49.00 & 000 \\
\hline
\end{tabular}

Dari hasil tersebut, terlihat bahwa mitra mengalami perubahan dan peningkatan kemampuan, dimana dari hasil awal rata-rata pemahaman mitra atas Trauma Healing terjadi 
Implementasi Trauma Healing Dalam Penanganan Anak Korban Tindak Pidana Kekerasan Seksual

Imam Maulana Yusuf, Siti Fatimah, Evi Noviawati

peningkatan. Dengan demikian, hal ini menunjukan bahwa pelaksanaan kegiatan pengabdian kepada masyarakat yang dikemas dalam bentuk Program Kemitraan Masyarakat Stimulus (PKMS) dari Kemenristek-Brin dapat diterima dengan baik dan menyebebkan terjadinya perubahan kapasitas berupa peningkatan wawasan dan kemampuan mitra dalam memecahkan permasalahan sosial, khususnya dalam mengatasi dan mencegah terjadinya depresi atau Post Traumatic Stress Disorder (PTSD) pada anak yang diakibatkan dari adanya tindakan kekerasaan seksual.

\section{KESIMPULAN DAN SARAN}

Dari hasil tahapan pelaksanaan kegiatan Program Kemitraan Masyarakat Stimulus (PKMS) mengenai Implementasi Trauma Healing pada anak korban kekerasan seksual yang berlokasi di Desa Pajaten Kecamatan Sidamulih Kabupaten Pangandaran, maka dapat disimpulkan kondisi mitra saat ini telah mengalami perubahan berupa peningkatkan kapasitas dan kemampuan diri atau life skill tentang metode penanganan dalam mengatasi trauma bagi anak yang mengalami kekerasaan seksual melalui play therapy dan self motivation yang dapat dilakukan di lingkungan keluarga.

Selanjutnya mengenai saran agar kegiatan tersebut memberikan dampak nyata dan luas dimasyarakat, diharapkan mitra dapat mendorong mitra untuk menyebarluaskan informasi serupa agar dapat mencegah terjadinya tindakan kekerasaan seksual dimasyarakat serta mendorong untuk menggagas dijadikannya Desa Pajaten Kecamatan Sidamulih Kabupaten Pangandaran sebagai desa layak anak.

\section{UCAPAN TERIMAKASIH}

Tim pelaksana kegiatan pengabdian kepada masyarakat dari Universitas Galuh, mengucapkan terimaksih yang sebesar-besarnya kepada DRPM Kemenristek-Brin yang telah bersedia membiayai Program Kemitraan Masyarakat Stimulus (PKMS) sehingga dapat dilaksanakan sesuai dengan harapan. Selanjutnya, ucapan terimkasih disampaikan kepada Pemerintah Desa Pajaten Kecamatan Sidamulih Kabupaten Pangandaran dan Kepada Dinas Keluarga Berencana, Pemberdayaan Perempuan dan Perlindungan Anak (DKBP3A) Kabupaten Pangandaran beserta seluruh pihak yang terlibat dalam pelaksanaan kegiatan ini. 


\section{DAFTAR PUSTAKA}

Andreas, P. dkk. (2017). Strategi Penanganan Anak Korban Kekerasan Seksual Oleh Lembaga Perlindungan Anak Provinsi Bali. Jurnal Humanis Unud, 18(1):269-275.

Banks, L.M., Kelly, S.A., Kyegombe, N., Kuper, H., Devrie, K. (2017). If he could speak, he would be able to point out who does those things to him": Experiences of violence and access to child protection among children with disabilities in Uganda and Malawi. PLOS ONE, 12(9):3. https://doi.org/10.1371/journal.pone.0183736

Gorda, AAA. Ngr. Tini Rusmini. (2017). Hukum Perlindungan Anak Korban Pedofilia. Malang: Setara Press.

Kusuma, A.A. (2015). Efektivitas Undang-Undang Perlindungan Anak Dalam Hubungan Dengan Perlindungan Hukum Terhadap Anak Korban Perdagangan Orang di Indonesia. Journal Lex et Societatis, III(1): 64.

Majalah Prospek. (2010). Trauma Healing. Nomor 6 Tahun 2 Triwulan 4, 2010.

Purwanti, A. dan Hardiyanti, M. (2018). Strategi Penyelesaian Tindak Kekerasan Seksual Terhadap Perempuan dan Anak Melalui Ruu Kekerasan Seksual. Masalah-Masalah Hukum (MMH), 47(2), 138-148.

Utami, P.N. (2018). Pencegahan Kekerasan Terhadap Anak Dalam Perspektif Hak Atas Rasa Aman di Nusa Tenggara Barat. Jurnal HAM. 9 (1): 4

Waluyo, B. (2011). Viktimologi Perlindungan Hukum Terhadap Korban Kejahatan. Jakarta: Sinar Grafika.

Wiguno, A.P. (2013). Kajian Viktimologi Terhadap Anak Sebagai Korban Tindak Pidana Kesusilaan. Jurnal Ilmu Hukum Legal Opinion, 1(1): 4. 